\title{
Something Has to Change: What Can Indiana Do to Save OUR Babies?
}

\author{
STAR S. MEYER ${ }^{*}$
}

\section{INTRODUCTION}

Why does Indiana have such a high infant mortality rate? What can healthcare providers and lawmakers do differently to decrease infant mortality rates in Indiana? Although the infant mortality rate in Indiana is recognized as a serious problem, it remains high year after year. ${ }^{1}$ The Indiana State Department of Health ("ISDH") recently announced that in 2018, Indiana experienced its largest decrease in infant mortality rates in six years. ${ }^{2}$ However, despite multiple organizations providing resources to address infant mortality in Indiana, we are not experiencing a sustained decrease in our rates. Recent legislation requiring hospitals to implement perinatal standards of care, in an effort to obtain a certification from the state, also will not decrease infant mortality. ${ }^{3}$

Once pregnancy begins, what often follows is a series of decisions that must be made in a system that can be difficult for anyone to navigate. ${ }^{4}$ Whether you are a single teenager in high school, or a married professional, pregnancy can potentially launch women into a healthcare system of which they may have little knowledge or experience.

Regardless of the intended outcome of the pregnancy, one of the first decisions that must be made early on is choosing a healthcare provider. ${ }^{5}$ There are different options for women seeking prenatal care. ${ }^{6}$ When choosing a prenatal care provider, it is possible that the first thought many people have is an obstetrician-gynecologist ("OB-GYN"). However, there are other options including board certified Family Medicine physicians and Certified Nurse Midwives (CNM). ${ }^{7}$ Despite these different options, "[a]pproximately one-third

* J.D. Candidate, 2020, Indiana University School of Law - Indianapolis; B.S.N., 2002, Saint Joseph's College.

1. Quality Improvement Comm., Addressing Infant Mortality in Indiana: A REPORT TO THE IPQIC GOVERnING COUNCIL 4 (Mar. 26, 2014), https:/www.in.gov/isdh/files/ Addressing_Infant_Mortality_in_Indiana.pdf[https://perma.cc/2CC2-ACU7].

2. Indiana Infant Mortality Rate Shows Biggest Decrease in 6 Years, Ind. ST. DeP'T HEALTH, https://calendar.in.gov/site/isdh/event/indiana-infant-mortality-rate-shows-biggestdecrease-in-6-years/ [https://perma.cc/2BYV-QETA].

3. Program to Certify Perinatal Levels of Care Designations for Licensed Hospitals and Birthing Centers That Provides Birthing Services, Ind. CodE ANN. § 16-21-13-1 (LexisNexis 2019).

4. See Office on Women's Health, Prenatal Care and Tests, U.S. DeP'T Health \& Human SERVS., https://www.womenshealth.gov/pregnancy/youre-pregnant-now-what/prenatal-care-andtests [https://perma.cc/B5TS-YKES].

5. See id.

6. $I d$.

7. $I d$. 
of Indiana mothers (31.9\%) do not receive prenatal care in their first trimester."

Along with prenatal care, a pregnant woman must also decide where to deliver her baby and begin thinking about a plan for the birth. ${ }^{9}$ In deciding where to deliver a baby, the choice is often deciding among a hospital, birthing center, or home. ${ }^{10}$ When it comes to choosing between hospitals, the reality is that if you have already chosen a healthcare provider, there is not much of an option as to where the delivery will occur. ${ }^{11}$ Healthcare providers are required to have privileges and to be credentialed in any hospital where they practice. ${ }^{12}$ If the healthcare provider does not have privileges at a certain hospital, then they cannot deliver babies there. ${ }^{13}$ Additionally, many rural communities have limited access to hospital services. ${ }^{14}$ In fact, in Indiana, fifty-two counties have less than two hospitals to choose from. ${ }^{15}$ Of those fifty-two counties, twenty-five counties have no hospitals that provide maternity care. ${ }^{16}$ All of this, combined with insurance restrictions on in-network healthcare providers, means mothers do not necessarily have many options in deciding which hospital will deliver their baby.

This is why it is puzzling that Governor Holcomb signed a new bill into law in 2018 that is supposed to decrease infant mortality. ${ }^{17}$ The purpose of the law, which went into effect on July 1, 2018, is to provide certifications of perinatal levels of care for hospitals and birthing centers. ${ }^{18}$ The rationale for the law is to assist new mothers in choosing which facility to deliver their baby. ${ }^{19}$ During news coverage on the new bill, Governor Holcomb stated, "[w] hen you think about the 623 babies that didn't make it past their first year in the state of Indiana, it's clear that we have work to do." ${ }^{20}$ The new law may be helpful for women in deciding

8. QuAlity IMPROVEMENT COMM., supra note 1 , at 8.

9. Office on Women's Health, supra note 4.

10. Id.

11. Obstetric Health Care Providers: Choosing One Right for You, ClEveland ClinIC (Apr. 26, 2017), https://my.clevelandclinic.org/health/articles/9698-obstetric-health-care-providerschoosing-one-right-for-you [https://perma.cc/4ZC7-58KV].

12. Hospital governing board; responsibilities, IND. ANN. CODE $§ 16-21-2-5$ (LexisNexis 1999).

13. See id.

14. Healthcare Access in Rural Communities, Rural Health Info. Hub, https://www. ruralhealthinfo.org/topics/healthcare-access [https://perma.cc/BG8Q-HZFY].

15. March of Dimes Found., Nowhere to Go: Maternity Care Deserts Across the U.S. 2 (2018), https://www.marchofdimes.org/materials/Nowhere_to_Go_Final.pdf [https://perma.cc/J8L7-B9GX].

16. See id. at 4.

17. Lauren Chapman, Holcomb Signs Bill to Reduce Infant Mortality, Standardize Care, WFYI INDIANAPOLIS (Mar. 8, 2018), https://www.wfyi.org/news/articles/holcomb-signs-bill-toreduce-infant-mortality-standardize-care [https://perma.cc/8KYS-TCHC].

18. Id.

19. Id.

20. Id. 
whether to deliver their baby in a birthing center versus a hospital. ${ }^{21}$ However, almost $99 \%$ of deliveries in the United States occur in a hospital..$^{22}$ Because many women in Indiana may not ultimately be choosing which hospital they will deliver their baby, we must question how this certification system would actually decrease infant mortality.

\section{A. The Issue}

More must be done to decrease the infant mortality rate in Indiana. As of December 2019, Indiana has the seventh highest infant mortality rate in the country. ${ }^{23}$ At issue is the focus of Indiana lawmakers in addressing infant mortality in the state. The new law, signed by Governor Holcomb effective July 1,2018 , implements a program to certify perinatal levels of care designations for licensed hospitals and birthing centers that provide birthing services. ${ }^{24}$ Providing expectant mothers with information on the quality of care provided in the hospital in which they are going to deliver a baby will hopefully provide peace of mind. However, it is difficult to imagine how requiring hospitals to meet criteria for certifications will decrease infant mortality in Indiana. The certification requirements are extremely complex and do not directly address the top causes of infant mortality. ${ }^{25}$ The long list of requirements to become certified as a Level I-IV facility does not offer ways to decrease the risks of the top causes of infant mortality. ${ }^{26}$ The requirements also do nothing to address the problem of maternity care deserts. ${ }^{27}$

Since this law will not solve the problem of infant mortality in Indiana, lawmakers should look at what drives the infant mortality rate in Indiana and address those specific issues. For example, especially in certain geographic locations, access to care specifically impacts infant mortality ${ }^{28}$ Lawmakers and

21. Id.

22. Marian F. MacDorman et al., Trends in Out-of-Hospital Births in the United States, 1990-2012, NAT'L CTR. FOR HeAlth Stat. 1 (Mar. 2014), https://www.cdc.gov/nchs/data/ databriefs/db144.pdf [https://perma.cc/MK64-59HV].

23. Infant Mortality Rates by State, Ctrs. For Disease Control \& Prevention, https://www.cdc.gov/nchs/pressroom/sosmap/infant_mortality_rates/infant_mortality.htm [https://perma.cc/C4MR-BRDB].

24. Program to Certify Perinatal Levels of Care Designations for Licensed Hospitals and Birthing Centers That Provides Birthing Services, IND. Code ANN. § 16-21-13-14 (LexisNexis 2019).

25. 410 IND. ADMIN. CodE 39 (2019), https://www.in.gov/isdh/files/18-416\%20-\%20Final\% 20Rule\%202.pdf [https://perma.cc/N3W5-FKH8].

26. See generally id. § 39-4-1.

27. $I d$.

28. Elaine Cox, U.S. Infant Mortality: a Case Study in Health Care Disparities, U.S. News \& World REP. (May 23, 2016, 10:50 AM), https:/health.usnews.com/health-news/patientadvice/articles/2016-05-23/us-infant-mortality-a-case-study-in-health-care-disparities 
healthcare providers should also assess methods used in states with lower infant mortality rates and consider using the same approaches. The current Indiana legislation will be ineffective in decreasing infant mortality rates. Indiana needs to use an evidence-based and multi-disciplinary approach to address this very serious problem. ${ }^{29}$

\section{B. Roadmap}

This Note discusses the consistently high infant mortality rate in Indiana and the need for meaningful steps to decrease infant mortality in this state. Section II provides a background of Infant mortality in the United States and in Indiana. This section includes causes and risk factors of infant mortality. Section II also looks at maternity care deserts and what other states are doing to lower infant mortality rates or to maintain lower rates than Indiana. Section III provides information on current Indiana legislation that was signed into law in 2018. The purpose of the legislation is to decrease infant mortality, so a breakdown of the statute is provided in this section. ${ }^{30}$ This section will also describe why the current law will not work to decrease infant mortality. Section IV discusses what organizations are doing, nationally and in Indiana, to help decrease infant mortality rates. It also gives a detailed description of other steps that Indiana could be taking to actually address risk factors and prevention of infant mortality, which would occur outside of the hospital setting. Section V concludes the Note by summarizing what Indiana needs to do to lower infant mortality. This Note analyzes the current situation and argues for a different approach to protect our babies.

\section{BACKGROUND OF THE ISSUE}

\section{A. What Is Infant Mortality?}

According to the Centers for Disease Control and Prevention (CDC), the definition of infant mortality is the death of an infant prior to his or her first birthday. ${ }^{31}$ The top five causes of infant mortality are: (1) birth defects, (2) preterm birth and low birth weight, (3) Sudden Infant Death Syndrome, (4) maternal complications, and (5) injuries. ${ }^{32}$ Infant mortality caused by injuries includes suffocation. ${ }^{33}$

Infant mortality is determined by calculating the number of infant deaths out

[https://perma.cc/QU54-36D4].

29. See Infant Mortality: What Is CDC Doing?, Ctrs. FOR Disease Control \& PREVENTION, https://www.cdc.gov/reproductivehealth/maternalinfanthealth/infantmortalitycdcdoing.htm [https://perma.cc/G765-YUCQ].

30. Chapman, supra note 17.

31. Infant Mortality, Ctrs. for Disease Control \& Prevention, https://www.cdc.gov/ reproductivehealth/MaternalInfantHealth/InfantMortality.htm [https://perma.cc/TBM7-UWC4].

32. Id.

33. Id. 
INDIANA DO TO SAVE OUR BABIES?

of every 1,000 live births. ${ }^{34}$ As of December 2019, the infant mortality rate in the United States is 5.8 infant deaths per 1,000 live births. ${ }^{35}$ For that same time period, the infant mortality rate in Indiana is significantly higher at $7.3 \mathrm{infant}$ deaths per 1,000 live births. ${ }^{36}$

Although there is no single cause of infant mortality, there are important factors to consider when addressing the issue. Important factors during pregnancy that ultimately impact infant mortality rates include: starting folic acid, immunizations for the mother, smoking cessation, alcohol use during pregnancy, drug use during pregnancy, and maternal obesity. ${ }^{37}$ According to the Indiana State Department of Health (ISDH), "[a]s a risk factor, obesity is associated with preterm births (obese $=25 \%$, morbidly obese $=33 \%$ ). The negative health outcomes associated with preterm births can also be risk factors for mortality and include low/very low birth weights, respiratory distress, and feeding issues." 38

\section{B. Maternity Care Deserts}

Like other areas in the country, many residents in Indiana live in maternity care deserts. ${ }^{39}$ The March of Dimes defines access to maternity care as, "availability of hospitals providing obstetric care, availability of providers offering obstetric care and access to that care through health insurance." ${ }^{\prime 40}$ Women who live in a maternity care desert live in a county that does not have obstetric providers or a hospital the providing obstetric care. ${ }^{41}$

Nationwide, 1,085 counties are maternity care deserts. ${ }^{42}$ This equates to over five million women living in a maternity care desert in the United States. ${ }^{43}$ Further, 150,000 babies are born to women living in maternity care desserts. ${ }^{44} \mathrm{In}$ Indiana, twenty-five counties are maternity care deserts. ${ }^{45}$

34. Infant Mortality Rates by State, Ctrs. For Disease Control \& Prevention, https://www.cdc.gov/nchs/pressroom/sosmap/infant_mortality_rates/infant_mortality.htm [https://perma.cc/E5TH-PTZH].

35. Infant Mortality, supra note 31.

36. Infant Mortality Rates by State, supra note 34.

37. See March of Dimes Found., March of Dimes Foundation Data Book for Policy Makers: Maternal, Infant, and Child Health in the United States 44-50, (2016), https://www.marchofdimes.org/March-of-Dimes-2016-Databook.pdf [https://perma.cc/BT97$67 \mathrm{HH}]$.

38. QuAlity IMPROVEMENT COMM., supra note 1 , at 8.

39. MARCH OF Dimes Found., supra note 15, at 2.

40. Id.

41. Id.

42. Id. at 1 .

43. Id.

44. Id.

45. Id. at 2 . 
Healthy pregnancies start with early access to care. ${ }^{46}$ That care and support is extremely important for early identification and treatment of serious health conditions of mothers and babies. ${ }^{47}$ Infants of mothers who live in maternity care deserts are at an increased risk of complications and death. ${ }^{48}$ It is essential that we address the problem of maternity care deserts in Indiana. How can women access early prenatal care in an effort to decrease infant mortality if they do not have access to care in their community? The state should work with hospitals and healthcare providers to develop a solution for providing care to mothers and their babies.

\section{Infant Mortality in Indiana}

Indiana has historically had one of the highest infant mortality rates in the country. ${ }^{49}$ Until 2018 , infant mortality numbers were announced by the ISDH, Indiana's infant mortality rate has been greater than 6.9 for over 100 years. ${ }^{50}$ There are likely many reasons that Indiana's infant mortality rate is high. ${ }^{51}$

One problem is that Indiana has an extremely high smoking rate among pregnant women. ${ }^{52}$ In fact, the smoking rate is twice that of the national average with one in five pregnant women smoking in Indiana. ${ }^{53}$ The Quality Improvement Committee of the ISDH points out that only eight states have a higher pregnancy smoking rate. ${ }^{54}$ This is important because of the negative impact that smoking has on infant mortality as a result of Sudden Unexpected Infant Death. ${ }^{55}$ In fact, a recent study showed that even smoking just one cigarette a day during pregnancy doubles the risk of Sudden Unexpected Infant Death. ${ }^{56}$

Smoking is one example where addressing the problem with maternity care deserts could have a meaningful impact on infant mortality. It seems that early and consistent access to care would provide more of an opportunity for healthcare providers to screen patients for smoking and provide assistance in smoking cessation. However, without access to care, it would be more difficult to provide this assistance.

Work has been done in Indiana in an effort to reduce infant mortality. In 2013, the ISDH stated that it was making infant mortality, and focused efforts in

46. See id. at 10 .

47. Do You Live in a Maternity Care Desert?, MARCH Dimes Found. (Oct. 25, 2018, 11:28AM), http://newsmomsneed.marchofdimes.org/?p=27523 [https://perma.cc/65JG-YT7W].

48. Id.

49. QuAlity IMPROVEMENT COMM., supra note 1, at 8.

50. Id.

51. See id. at 9.

52. $I d$. at 22 .

53. Id. at 8 .

54. Id.

55. Tatiana M. Anderson et al., Maternal Smoking Before and During Pregnancy and the Risk of Sudden Unexpected Infant Death, 143 PEDIATRICS 1, 4 (2019).

56. Id. at 1 . 
INDIANA DO TO SAVE OUR BABIES?

decreasing the infant mortality rate in Indiana, its top priority. ${ }^{57}$ The ISDH stated, "[i]nfant mortality reflects the health of a population at large and serves as a key indicator of a community's health and care resources." ${ }^{.58}$ The ISDH seemed to recognize that decreasing infant mortality can actually impact the overall health of Indiana, which is one of the reasons that they chose to make this effort a priority. ${ }^{59}$

Indiana held its first Infant Mortality Summit in $2013 .{ }^{60}$ The Governor at the time, Mike Pence, spoke at the Summit. ${ }^{61}$ At that time, data from 2010 showed that Indiana's infant mortality rate was the seventh highest in the country. ${ }^{62}$ This summit was five years ago, and as of the publication of this note, Indiana has the same ranking in infant mortality. ${ }^{63}$

In 2014, the Quality Improvement Committee of the Indiana Perinatal Quality Improvement Collaborative put together recommendations for decreasing Indiana's infant mortality rate. ${ }^{64}$ The report included: (1) a background overview of infant mortality in Indiana and in the United States; (2) an assessment and explanation of the complexity of addressing this issue; (3) an assessment of the approaches by other states to decrease infant mortality that have been successful; (4) an explanation of Indiana's strengths and weaknesses in addressing this problem; (5) an explanation of how decreasing Indiana's infant mortality rate would benefit Indiana; (6) an explanation of Indiana's current infant mortality rate and recommendations for improvement. ${ }^{65}$ Despite this work and focused effort by the Quality Improvement Committee, Indiana's infant mortality rate has not significantly decreased. ${ }^{66}$

As previously mentioned, Indiana has a higher infant mortality rate than the national infant mortality rate. If Indiana's infant mortality rate was the same as the national rate, there would have been 118 fewer infant deaths in Indiana in $2016 .{ }^{67} \mathrm{We}$ must assess what other states are doing to accomplish significantly lower infant mortality rates than Indiana. We must also specifically address the impact that smoking has on infant mortality in Indiana. Decreasing the smoking rate in Indiana could decrease the risk of Sudden Unexpected Infant Death, which would impact our infant mortality rate.

57. QuALiTy IMPROVEMENT COMM., supra note 1, at 4.

58. Id.

59. See id.

60. Id. at 7 .

61. Id.

62. Id.

63. Infant Mortality Rates by State, supra note 23.

64. Quality ImProvement Comm., supra note 1, at 4-5.

65. Id.

66. Infant Mortality Rates by State, supra note 23.

67. Ind. State Dep't of Health, Infant Mortality Disparities 2016, (2016), https:/www.in.gov/isdh/files/IM\%20Disparities\%202016.pdf [https://perma.cc/7M4H-79LP]. 


\section{Infant Mortality throughout the United States}

Indiana has an opportunity to learn from successes in other parts of the country. Like the variance in infant mortality rates from county to county in Indiana, there is a great deal of difference in infant mortality rates between the states. ${ }^{68}$ The geographic locations with the lowest infant mortality rates are on the east and west coasts with Washington, Oregon, California, New York, New Jersey, Vermont, New Hampshire, Massachusetts, and Connecticut all having infant mortality rates below the national average. ${ }^{69}$ The states with the highest infant mortality rates are primarily in the south and include Oklahoma, Tennessee, Georgia, Delaware, Louisiana, Arkansas, Mississippi, and Alabama. ${ }^{70}$ Indiana and Ohio have the highest infant mortality rates in the Midwest. ${ }^{71}$

While infant mortality rates have remained unchanged nationwide, California has experienced a $37 \%$ decrease from 1994-2015. ${ }^{72}$ A lot of the focus in California has been on the health and safety of pregnant women. ${ }^{73}$ California's journey in decreasing infant mortality rates began with collecting data over a twenty year period and looking at what caused infant deaths in the state. ${ }^{74} \mathrm{~A}$ database was created by the California Perinatal Quality Care Collaborative and is where California hospitals could enter their data and compare themselves to other Neonatal Intensive Care Units (NICU) in the state. ${ }^{75}$ The data entered is related to infant deaths and complications and is paid for by the state of California. $^{76}$

In reviewing the data in California, one specific hospital was able to see that it had a significantly higher rate of brain bleeds in infants in its NICU than other hospitals. ${ }^{77}$ Understanding that intracranial hemorrhages are a leading cause of death in premature babies, this became actionable data when the hospital implemented evidence-based strategies to decrease brain bleeds in its NICU. ${ }^{78}$ The strategies included steroid shots for women in preterm labor, delayed umbilical cord clamping, and hospital wide training for staff on how to create a calm environment for premature infants in the hospital. ${ }^{79}$ The outcome was that

68. Infant Mortality Rates by State, supra note 23.

69. Id.

70. Id.

71. Id.

72. Lucile Packard Found. for Children, Learn More about Infant Mortality, KIDSDATA.ORG, https://www.kidsdata.org/topic/294/infantmortality/table [https://perma.cc/3NEM-CD3U].

73. Id.

74. Anna Almendrala, How California Became the Only State to Lower its Infant Mortality Rate, Huffington Post (Aug. 9, 2018, 10:56PM), https:/www.huffpost.com/entry/californiainfant-mortality-premature-babies_n_5b6b650de4b0bdd062062348 [https://perma.cc/4L3T-6XSZ].

75. Id.

76. $I d$.

77. Id.

78. Id.

79. Id. 
INDIANA DO TO SAVE OUR BABIES?

within three years the hospital saw its rate of brain bleeds decrease from approximately $15 \%$ to $3.8 \%{ }^{80}$ The number of deaths in the NICU of that hospital decreased by almost half in that time. ${ }^{81}$ The doctors of the hospital credited the rapid improvement to having actionable real-time data that allowed interventions to be implemented quickly. ${ }^{82}$

Maryland has an only slightly lower infant mortality rate than Indiana at 6.4. ${ }^{83}$ However, areas in Maryland have had some success stories that we could learn from. The B'more for Healthy Babies Initiative is an approach used in Baltimore. ${ }^{84}$ The program began in 2009 and uses public and private funding (a "collaborative funding model"). ${ }^{85}$ Efforts in the program include: public education campaigns; home visits for pregnant women; and "collaborations with clinics and hospitals to make contraception more accessible." ${ }^{\prime \prime 6}$ The result of the program was that the infant mortality rate, in the area served, fell by $35 \% .{ }^{87}$ Other successes from the B'more for Healthy Babies Initiative were that the disparity between African-American infant deaths and deaths of white infants decreased by $64 \%$; teen birth rate decreased by $49 \%$; and sleep related infant deaths decreased by $71 \%{ }^{88}$

Another program in Montgomery County in Maryland has been working to reduce the disparity between African-American infant deaths and deaths of Caucasian infants. ${ }^{89}$ The infant mortality rate in that area was only $4.8 .^{90}$ However, the rate was 3.6 for Caucasian county residents and 8.3 for African American county residents. ${ }^{91}$ Montgomery County used a Fetal Infant Mortality Review Board to actually determine the reasons for infant mortality. They then used this information to determine next steps and interventions. ${ }^{92}$

Lawmakers in Indiana can certainly evaluate the successes of other

80. $I d$.

81. Id.

82. Id.

83. Infant Mortality Rates by State, supra note 23.

84. Using Collective Impact to Reduce Infant Mortality in Baltimore City, ANNIE E. CASEY Found. (June 22, 2018), https://www.aecf.org/blog/using-collective-impact-to-reduce-infantmortality-in-baltimore-city/?gclid=EAIaIQ obChMIsrT1v7eE3 gIVhISzCh 3QTwvEAAYASAAEgJYvfD_BwE[https://perma.cc/5N2C-QZVE].

85. Id.

86. Id.

87. Id.

88. Id.

89. Laura Jenkins, Working to Reduce Infant Mortality in Maryland, WASH. Post (Jan. 15, 2016), https://www.washingtonpost.com/opinions/working-to-reduce-infant-mortality-inmaryland/2016/01/14/027e078c-b310-11e5-9388-466021d971de_story.html?noredirect= on\&utm_term=.3bb3c5a5e2c1 [https://perma.cc/6QQY-ZMXY].

90. Id.

91. Id.

92. Id. 
communities and other states. In Indiana, we should look at the success that a state like California has had in decreasing their infant mortality rates and determine if the same interventions can be used in Indiana. ${ }^{93}$ Like California, Indiana has a Perinatal Quality Improvement Collaborative. ${ }^{94}$ However, not all collaboratives are the same. ${ }^{95}$ California's was the first and it will take Indiana time to build something similar. ${ }^{96}$ However, it is also important that the Indiana Perinatal Quality Improvement Collaborative provide hospitals with assistance to actually implement improvement initiatives. ${ }^{97}$ Simply providing education and resources will not make meaningful changes to infant mortality rates. ${ }^{98}$ Certainly, requiring hospitals to spend money and resources to obtain a certification from the ISDH will not make meaningful changes to infant mortality rates.

We can also evaluate successes that smaller communities have had, such as B'more for Healthy Babies Initiative, and try to implement those on a larger scale in Indiana.${ }^{99}$ Fortunately, Senate Bill 278 passed in the Indiana Senate in February $2019 .{ }^{100}$ The bill became law on July 1, 2019, which means the ISDH will assist with oversight of local Fetal-Infant Mortality Review Teams. ${ }^{101}$ Hopefully, like Montgomery County in Maryland, data collected from Fetal-Infant Mortality Review Teams can be used to improve care and access to resources in communities in Indiana.

\section{LEGISLATION TO IMPROVE INFANT MORTALITY}

\section{A. Indiana Legislation}

The current Indiana legislation, which focuses on requiring hospitals to obtain certifications from the ISDH, likely will not decrease infant mortality. ${ }^{102}$ For example, a healthy full-term pregnancy is an important factor in decreasing the risk of infant mortality. ${ }^{103}$ In order to decrease the risk of pre-term birth we must

93. Lucile Packard Found. for Children, supra note 72.

94. QuAlity IMPROVEMENT COMM., supra note 1, at 4.

95. Almendrala, supra note 74.

96. Id.

97. See id.

98. Id.

99. Using Collective Impact to Reduce Infant Mortality in Baltimore City, supra note 84.

100. Leising: Bill to address Indiana's high infant mortality rate passes Senate, IND. SENATE REPUBLICANS (Feb. 5, 2019), https:/www.indianasenaterepublicans.com/leising-bill-to-addressindiana-s-high-infant-mortality-rate-passes-senate [https://perma.cc/5VNM-7LFN].

101. Id. See generally Fetal-Infant Mortality Review Teams, Ind. CodE ANN. § 16-49-6 (LexisNexis 2019).

102. Program to Certify Perinatal Levels of Care Designations for Licensed Hospitals and Birthing Centers That Provides Birthing Services, Ind. Code ANN. § 16-21-13-1 (LexisNexis 2019).

103. Promoting Health for Infants, CTrS. For Disease Control \& Prevention, https://www. cdc.gov/chronicdisease/resources/publications/factsheets/infant-health.htm?CDC_AA_ refVal=https $\% 3 \mathrm{~A} \% 2 \mathrm{~F} \% 2 \mathrm{Fwww} . c d c$. gov $\% 2 \mathrm{Fchronicdisease} \% 2$ Fresources $\% 2$ Fpublications $\% 2 \overline{\mathrm{F}}$ 
focus on interventions such as improving access to perinatal care and smoking cessation. ${ }^{104}$ However, the standards used to certify levels of care do not accomplish that. ${ }^{105}$

To understand the legislation, it is helpful to read the actual verbiage in the statute. IC $\S 16-21-13-1$ states, "[t]he state department shall establish a program to certify perinatal levels of care designations for every hospital and birthing center licensed under this article that provides birthing services. (b)The program must include obstetrics level certification and neonatal level certification." ${ }^{106}$ This section gives the ISDH the authority to establish the levels of care for both the obstetrics and neonatal programs of hospitals and birthing centers.

I.C. § 16-21-13-2 explains the authority of the ISDH and states:

The state department may do any of the following: (1) Change the perinatal level of care designation for a hospital or birthing center if the state department determines that the hospital or birthing center failed to meet the standards necessary for the designated perinatal level of care. (2) Investigate a complaint against a hospital or birthing center concerning a perinatal certification. ${ }^{107}$

IC $\S 16-21-13-3$ provides explanation of licensed hospitals/birthing centers as well as duties and peer review. ${ }^{108}$ The statute specifically states:

(a) A hospital or birthing center licensed under this article that offers birthing services may operate as a perinatal center if the hospital or birthing center complies with the perinatal certification requirements of the following: (1) The American Academy of Pediatrics. (2) The American College of Obstetricians and Gynecologists. (b) A perinatal center may perform peer review (as described in IC 34-30-15) for: (1) the perinatal center; (2) other hospitals; or (3) other birthing centers; that offer birthing services. This subsection does not prevent a perinatal center from performing its own peer review. (c) Peer review performed by a perinatal center under this chapter must comply with IC 34-30-15. ${ }^{109}$

\footnotetext{
aag\%2Finfant-health.htm [https://perma.cc/86Z5-KNJ7].

104. See id.

105. See Revised Indiana Perinatal Hospital Standards, Ind. State DeP't of Health 1, 4-27 (June 16, 2015), https://www.in.gov/laboroflove/files/Revised_Perinatal_Hospital_ Standards_6.15.pdf [https://perma.cc/4EEM-BKXU].

106. Program to certify perinatal levels of care designations for licensed hospitals and birthing centers that provides birthing services, IND. CODE ANN. § 16-21-13-1 (LexisNexis 2019).

107. Authority of State Department, IND. CODE ANN. § 16-21-13-2 (LexisNexis 2019).

108. Licensed Hospitals or Birthing Centers; Duties-Peer Review, IND. CodE ANN. § 16-2113-3 (LexisNexis 2019).

109. Id.
} 


\section{B. Perinatal Hospital Services Levels of Care}

To guide the work of the program of certifying perinatal levels of care, Indiana has adopted the "Revised Perinatal Hospital Standards of 2015."110 Hospitals and birthing centers will be measured by six standards in Obstetrics. ${ }^{11}$ There are also an additional five standards for Neonatal and four standards for the entire facility. ${ }^{12}$ The first standard is Organization and relates to the neonatalperinatal programs of the hospital. ${ }^{113}$ The second standard is Obstetrical Unit Capabilities. ${ }^{14}$ Obstetrical Unit Capabilities is the resources, supplies, and staffing available on the unit where deliveries will occur. ${ }^{15}$ The third is Obstetric Personnel and is related to the availability and roles of hospital personnel. ${ }^{116}$ This includes personnel such as obstetrics providers, anesthesia providers, radiologists, medical specialists, surgeons, and registered nurses $(\mathrm{RN}){ }^{117}$ The fourth standard is Obstetric Support Personnel and is related to support services such as pharmacists, lactation consultants, social workers, RN case managers, blood bank technicians, and bereavement specialists. ${ }^{118}$ The fifth standard is Obstetric Equipment and includes such things as radiology equipment and resuscitation equipment and supplies. ${ }^{119}$ The sixth standard is Obstetric Medications and, in addition to requiring all resuscitation medications, it provides a list of medications that must be available to the Obstetrics unit. ${ }^{120}$ The seventh standard is Neonatal Unit Capabilities. ${ }^{121}$ The eighth standard is Neonatal Personnel and includes staffing requirements and the availability of certain consultants. ${ }^{122}$ The ninth standard is Neonatal Support Personnel, which includes requirements for certain support staff such as Radiology and Blood Bank. ${ }^{123}$ The tenth standard is Neonatal Equipment and the eleventh standard is Neonatal Medication. ${ }^{124}$ Standard twelve is for Laboratory requirements for Obstetrics and Neonatal. ${ }^{125}$

110. Jon Davis, Indiana Puts Perinatal 'Levels of Care' Standards into State Law to Reduce Infant Mortality, CouncIL ST. Gov'T (Sept. 2018), https://www.csgmidwest.org/policyresearch/ 0918-perinatal-levels-of-care.aspx [https://perma.cc/BB4L-RV85].

111. Id.

112. Revised Indiana Perinatal Hospital Standards, supra note 105, at 16-28.

113. Id. at 2 .

114. Id.

115. Id.

116. $I d$.

117. Id. at 8-11.

118. Id. at 11-12.

119. Id. at 12-13.

120. Id. at 13-14.

121. Id. at 16-17.

122. Id. at 17-21.

123. Id. at 21-22.

124. Id. at 22-23.

125. Id. at 24 . 
Standards thirteen through fifteen are Education, Performance Improvement, and Policies and Protocols for the facility. ${ }^{126}$

Within each standard is a set of written criteria and those criteria are used to assign the hospital or birthing center's level of care certification. ${ }^{127}$ The levels of certification available are levels I - IV for Obstetrics and Neonatal. ${ }^{128}$ The Revised Indiana Perinatal Hospital Standards provide a brief description of each level of certification under the Obstetrical definitions and Neonatal definitions. ${ }^{129}$

As you can see, the levels of certification are very specific and have complex requirements. ${ }^{130}$ However, the requirements within the standards for the levels of care do little to specifically address prevention of birth defects, preterm birth and low birth weight, Sudden Infant Death Syndrome, maternal complications, or injuries. ${ }^{131}$ If the standards do not address the top five causes of infant mortality, how could the requirements have a substantial impact on actually reducing infant mortality? ${ }^{132}$

Instead of requiring hospitals to spend money and resources in meeting the requirements for the levels of certification, the state should partner with healthcare providers to decrease risk of infant mortality. It seems that the best way to decrease risk of infant mortality would be to focus on the causes of infant mortality and work to eliminate those causes as much as possible. Lawmakers should also focus on the issue of maternity care deserts in this state. ${ }^{133}$ Incentivizing providers and hospitals to expand services to underserved communities in Indiana would provide an opportunity for early identification of risks for infant mortality. ${ }^{134}$ This would be a much more impactful use of resources than requiring existing hospitals that provide maternity care to obtain a certification by meeting standards that do not address the top risks of infant mortality.

\section{MORE MEANINGFUL STEPS TO DECREASE INFANT MORTALITY IN INDIANA}

The Quality Improvement Committee for the ISDH points out that there are a great deal of resources available to decrease infant mortality. ${ }^{135}$ However, we lack a coordinated effort in putting it all together to actually improve infant mortality rates. ${ }^{136}$ Indiana needs to use an evidence-based and multi-disciplinary

126. Id. at 24-28.

127. Id. at $6,9,14,17,22,26$.

128. $I d$. at $4-5$.

129. See generally id.

130. See id. at 24-27.

131. See id.

132. Infant Mortality, supra note 31.

133. MARCh OF Dimes Found., supra note 15, at 10.

134. Id.

135. QuAlity ImPRovement Comm., supra note 1, at 4.

136. See id. 
approach to take steps in actually decreasing infant mortality.

\section{A. What Non-profits Are Doing to Address Infant Mortality}

Other organizations within local communities have also been involved in the attempt to decrease infant mortality across the state. For example, Indiana University Health has invested in a Safe and Sound Sleep program in an effort to achieve one of its primary goals of decreasing infant mortality in Indiana. ${ }^{137}$ Recognizing that the third leading cause of infant mortality in Indiana is sleep related deaths, Indiana University Health hospitals send each baby home with a sleep sack and provide parents with education and tools for safe sleep. ${ }^{138}$ Also, St. Vincent Hospital sends Safe Sleep Bundles home with new parents. ${ }^{139}$ Recognizing the importance of safe sleep in decreasing infant mortality, St. Vincent is able to send parents home with a sleep sack, a pack-n-play with a sheet, and a safe sleep booklet. ${ }^{140}$

Franciscan Health made reducing infant mortality a system-wide community health goal in 2016. ${ }^{141}$ Franciscan Health states, "[f]rom Mooresville to Crawfordsville to Hammond, programs are designed to help educate and empower parents. Our programs provide education, supplies, counseling and resources to pregnant and new mothers through one-on-one interactions. Participants report less stress, better bonding and confidence in their parenting abilities." ${ }^{142}$ One example is the Grace Project in Indianapolis, which helps mothers and babies recovering as a result of a mother's substance abuse. ${ }^{143}$ Another example is a program in Lafayette for smoking cessation and breastfeeding support. ${ }^{144}$

Community Health Network hosted an Infant Mortality Summit in July

137. Ind. U. HeAlth, SAFE AND Sound SleEP, https://cdn.iuhealth.org/resources/09501010_Community_Impact_Report_WEB_3.pdf?mtime=20180117141750 [https://perma.cc/6LMANBX3]

138. Id.

139. 2018 Associates Campaign Highlighted Projects, Ascension St. VinCENT Found. (2018), https://give.stvincent.org/2018ACProjects [https://perma.cc/9PVU-FH5T].

140. Id.

141. Franciscan Health, InSPIRING Health: 2017 Community Benefit Report 4 (2017), http://images.franciscanhealthcare.org/PDFs/Enterprise/CBSA/community-benefit-report-2017.pdf [https://perma.cc/9V55-YLKZ].

142. Id.

143. Help Precious Babies Have a Better Start to Life Through the Grace Project, FRANCISCAN HEALTH, https://www.franciscanhealth.org/news-and-events/news/help-preciousbabies-have-better-start-life-through-grace-project [https://perma.cc/7QDF-X7C5].

144. Tobacco Cessation, FrAnCISCAN HeALTH, https://www.franciscanhealth.org/health-careservices/tobacco-cessation-457 [https://perma.cc/DE3T-4RHM]. Lactation Services, FRANCISCAN HEALTH, https://www.franciscanhealth.org/health-care-services/lactation-specialists-193 [https://perma.cc/E74Z-KGMJ]. 
INDIANA DO TO SAVE OUR BABIES?

2018. ${ }^{145}$ Over 100 people attended and included representatives from Community Health Network as well as "IU Health, St. Vincent Health, Eskenazi Health, Anthem Indiana Medicaid, the Marion County Public Health Department, the Indiana House of Representatives, the Indiana Senate, the Minority Health coalition, the March of Dimes, the Urban League, and Indiana Family and Social Services Administration." ${ }^{146}$ Community Health Network's website states, "[t]he four-hour event included the review of recent data regarding infant mortality rates; group discussions related to opportunities for improvement; and the development of action plans to promote positive change." 147 This summit is a great example of the collaborative work that needs to occur. It is excellent that members of the Indiana House of Representatives and the Indiana Senate were present. ${ }^{148}$ The question remains, however, what lawmakers will do to make meaningful improvement in infant mortality rates in Indiana.

The Nurse-Family Partnership is a national organization and is a community health program. ${ }^{149}$ The program provides a visiting nurse to first time mothers who qualify, which begins during pregnancy and continues until the child turns two years old. ${ }^{150}$ The Nurse-Family Partnership reports that their program results in an $18 \%$ decrease in preterm deliveries and a $21 \%$ increase in the number of newborns breastfed. ${ }^{151}$

The March of Dimes Foundation also does a great deal of work and has developed a data book for policy makers. ${ }^{152}$ The March of Dimes Foundation states, "[t]oday, the Foundation works to improve the health of women, infants, children and families by preventing birth defects, premature birth and infant mortality through research, community services, education and advocacy."153

A lot of great work and collaboration is already occurring, and the state should consider assisting with coordination of these efforts. Assistance from the ISDH on expanding efforts such as access to care, smoking cessation, breastfeeding support, and substance abuse recovery in our hospital systems would be a better use of resources than implementation of levels of certification.

145. Press Release, Community Health Network, Community Health Network hosts Infant Mortality Summit (July 26, 2018), https:/www.ecommunity.com/news/2018/community-healthnetwork-hosts-infant-mortality-summit [https://perma.cc/HSM8-8FE4].

146. Id.

147. Id.

148. Id.

149. Nurse-Family Partnership Overview, Nurse-FAm. PARTnership (2018), https://perma.cc/R8EP-CSDC.

150. Id.

151. Nurse-Fam.P'ship, Nurse-Family Partnership Continues to Improve the Health OF OUR CHILDREN (2017), https:/www.nursefamilypartnership.org/wp-content/uploads/2017/ 02/2017-Thorland-NFP-Research-Outcomes.pdf [https://perma.cc/AP7F-ZJEV].

152. See generally MARCh OF Dimes Found., supra note 37.

153. Id. at iii. 


\section{B. What Other Professional Organizations Recommend}

Professional organizations such as the American College of Obstetricians and Gynecologists and the American Academy of Pediatrics are also involved in the attempt to decrease infant mortality. Support, research, and education from professional organizations can provide helpful insights from clinicians most involved and impacted by infant mortality.

The American College of Obstetricians participates in the Fetal and Infant Mortality Review. ${ }^{154}$ The American College of Obstetricians website states, "Fetal and Infant Mortality Review (FIMR) is a community-based and action-oriented process used to improve service systems and resources for women, infants[,] and families. This evidence-based method examines fetal and infant deaths, determines preventability, and engages communities to take action."

Considering the recommendations of professional organizations might also be helpful for Indiana in efforts to decrease infant mortality.

\section{Reducing Babies' Risk}

Many organizations in Indiana are doing a lot of important work to decrease infant mortality. However, a lot of that work is focused on safe sleep. Although safe sleep is extremely important in decreasing a baby's risk, there are other steps that we should be taking to make meaningful progress in decreasing infant mortality. ${ }^{155}$

It would be easier to decrease infant mortality if there were concrete ways to prevent those things that cause infant deaths, but that is not the case. ${ }^{156}$ However, work can be done to decrease the risks of the top causes of infant death. ${ }^{157}$ As previously mentioned, the top five causes of infant mortality are: (1) birth defects, (2) preterm birth and low birth weight, (3) Sudden Infant Death Syndrome, (4) maternal complications, and (5) injuries. ${ }^{158}$ It seems logical that addressing the risk factors for those top causes of infant mortality, especially for those people who experience higher infant mortality rates, would assist in decreasing infant mortality.

154. National Fetal and Infant Mortality Review (NFIMR), AM. C. OBSTETRICIANS, https://perma.cc/RY9K-BGD3.

155. Sudden Unexpected Infant Death and Sudden Infant Death Syndrome, CTRS. FOR DISEASE Control \& Prevention, https://www.cdc.gov/sids/Parents-Caregivers.htm\#additional [https://perma.cc/29XQ-AE28].

156. Are there ways to reduce the risk of infant mortality?, EUNICE KENNEDY SHRIVER NAT'L Inst. Child Health \& Human Dev. (Dec. 1, 2016), https://www.nichd.nih.gov/health/topics/ infant-mortality/topicinfo/reduce-risk [https://perma.cc/K23N-TLFV].

157. Id.

158. Infant Mortality, supra note 31. 


\section{Decreasing risk of birth defects.}

The leading cause of infant mortality in the United States is birth defects. ${ }^{159}$ Birth defects can be structural or functional/developmental, and are present at birth. ${ }^{160}$ Birth defects can cause a number of disabilities and health problems. ${ }^{161}$ The types of structural birth defects include: cleft lip and palate, heart defects, abnormal limbs, and neural tube defects. ${ }^{162}$ Neural tube disorders involve problems with the brain and problems with the spine, such as spina bifida. ${ }^{163}$ The types of functional/developmental birth defects include: nervous system problems, brain problems, sensory problems, metabolic disorders, and degenerative disorders. ${ }^{164}$

The birth defect rate in the United States is one in every thirty-three births. ${ }^{165}$ Risk factors for birth defects include: folic acid deficiency, alcohol consumption, smoking during pregnancy, drug use, certain medications, infections, obesity, diabetes, and environmental exposures. ${ }^{166}$ There are things that can be done to address these risk factors. For example, folic acid deficiency increases the risk of neural tube defects. ${ }^{167}$ Because of this risk, the CDC recommend that pregnant women and women who plan to become pregnant consume 400 micrograms of folic acid each day. ${ }^{168}$ This level of folic acid can be found in vitamins that are sold over the counter at most pharmacies. ${ }^{169}$ Unfortunately, however, only $40 \%$ of women who are of childbearing age are ingesting the recommended amount of folic acid. ${ }^{170}$ Early access to perinatal care could be an opportunity to educate women on the amount of folic acid they should be ingesting to protect their babies. ${ }^{171}$

159. Id.

160. Birth Defects, Eunice Kennedy Shriver Nat'L Inst. Child Health \& Human Dev., https://www.nichd.nih.gov/health/topics/birthdefects [https://perma.cc/62GQ-ESNH].

161. Id.

162. Id.

163. Id.

164. What are the types of birth defects?, EUNICE KENNEDy SHRIVER NAT'L Inst. CHILD HEALTH \& HuMAN DEV., https://www.nichd.nih.gov/health/topics/birthdefects/conditioninfo/types [https://perma.cc/H4AD-UKH7].

165. Birth Defects, supra note 160.

166. What are the types of birth defects?, supra note 164.

167. How many people are affected by/at risk for birth defects?, EUNICE KENNEDY SHRIVER NAT'L INST. CHILD HEALTH \& HuMAN DEV., https://www.nichd.nih.gov/health/topics/birthdefects/ conditioninfo/risk [https://perma.cc/N2QA-VQPV].

168. Id.

169. Folic Acid, Ctrs. For Disease Control \& Prevention https://www.cdc.gov/ ncbddd/folicacid/about.html [https://perma.cc/23AB-MWEE].

170. How many people are affected by/at risk for birth defects?, supra note 167.

171. Id. 


\section{Addressing the risks associated with preterm birth.}

Preterm birth is the birth of a baby prior to the end of the thirty-seventh week of pregnancy. ${ }^{172}$ Preterm births result in a higher risk of death and disability and approximately $10 \%$ of pregnancies result in preterm birth. ${ }^{173}$ Although there are known risks for preterm birth, causes are often unknown and difficult to prevent. ${ }^{174}$ The CDC is collaborating with other organizations to address preterm births. ${ }^{175}$ The focus is on increasing awareness of preterm births in an effort to prevent preterm births and to address challenges faced by infants who are born preterm. ${ }^{176}$ Because preterm births are often unexpected, prevention based on risk factors and the ability to address outcomes are important steps in decreasing the risk of infant mortality. ${ }^{177}$

\section{Addressing the risks associated with low birth weight.}

The CDC defines low birth weight as an infant weighing less than five and a half pounds immediately after birth. ${ }^{178}$ Low birth weight can occur in infants born preterm and also in infants born at full term. ${ }^{179}$ Low birth weight puts babies at higher risk for complications, including illness. ${ }^{180}$ The risk factors for low birth weight in infants include: smoking during pregnancy; alcohol consumption during pregnancy; history of preterm labor; maternal age of less than fifteen years old or more than thirty-five years old; environmental exposures (including lead in drinking water); and poor maternal weight gain during pregnancy. ${ }^{181}$ Weight gain recommendations are based on a woman's body mass index (BMI) before she became pregnant. ${ }^{182}$ Approximately $21 \%$ of pregnant women are below the recommended weight gain for pregnancy. ${ }^{183}$ Other risk factors for low birth

172. Preterm Birth, Ctrs. For Disease Control \& Prevention, https://www.cdc. gov/reproductivehealth/maternalinfanthealth/pretermbirth.htm [https:/perma.cc/7E7Z-WCVE].

173. Id.

174. Are there ways to reduce the risk of infant mortality?, supra note 156.

175. CDC Preterm Birth Activities, Ctrs. for Disease Control \& Prevention, https://www.cdc.gov/reproductivehealth/maternalinfanthealth/pretermcdc-activities.html [https://perma.cc/4JGP-LV57].

176. Are there ways to reduce the risk of infant mortality?, supra note 156.

177. Id.

178. Reproductive and Birth Outcomes, Ctrs. FOr Disease Control \& Prevention, https://ephtracking.cdc.gov/showRbLBWGrowthRetardationEnv.action [https://perma.cc/58989GAT] (last updated Oct. 26, 2016).

179. Are there ways to reduce the risk of infant mortality?, supra note 156.

180. Reproductive and Birth Outcomes, supra note 178.

181. Id.

182. See id.

183. Weight Gain During Pregnancy, Ctrs. for Disease Control \& Prevention, https://www.cdc.gov/reproductivehealth/maternalinfanthealth/pregnancy-weight-gain.htm [https://perma.cc/23SX-88UF]. 
INDIANA DO TO SAVE OUR BABIES?

weight are socioeconomic and include: income, education and marital status, stress, abuse, and domestic violence. ${ }^{184}$

Addressing risks associated with low birth weight should involve a combination of screening, education, and support. ${ }^{185}$ For example, a pregnant woman who smokes will likely need assistance to stop smoking. ${ }^{186}$ Like preterm birth, early and consistent access to prenatal care allows for identification of risk factors as well as treatment and support to decrease the risk of low birth weight. ${ }^{187}$ injuries.

4. Addressing the risks associated with Sudden Infant Death Syndrome and

According to the Centers for Disease Control and Prevention, "[s]udden unexpected infant death (SUID) is a term used to describe the sudden and unexpected death of a baby less than (one) year old in which the cause was not obvious before investigation." ${ }^{188}$ Although the risk of Sudden Infant Death Syndrome is unknown, through research, experts have been able to identify risk factors and recommendations for decreasing that risk. ${ }^{189}$

Sudden Infant Death Syndrome is a subcategory of Sudden Unexpected Infant Death, which also includes accidental suffocation while the baby is in a sleeping environment. ${ }^{190}$ As previously mentioned, infant mortality caused by injuries includes suffocation. ${ }^{191}$

One recommendation for decreasing the risk of Sudden Infant Death Syndrome and Sudden Unexpected Infant Death is related to educating pregnant mothers on the importance of refraining from smoking and using drugs and alcohol. ${ }^{192}$ This is another example of the importance of early and consistent access to prenatal care for identification of risk factors and education. In fact, one of the risk factors for Sudden Infant Death Syndrome is poor prenatal care. ${ }^{193}$ The CDC also recommends breastfeeding as a method of decreasing the risk of Sudden Infant Death Syndrome and Sudden Unexpected Infant Death. ${ }^{194}$ Parents should also prevent their babies from being too warm. ${ }^{195}$ Other steps in decreasing

184. Reproductive and Birth Outcomes, supra note 178.

185. Id.

186. Id.

187. Id.

188. About SUID and SIDS, CTRS. FOR DiSEASE CONTROL \& PREVENTIOn, https://www.cdc. gov/sids/about/index.htm?CDC_AA_refVal=https $\% 3 \mathrm{~A} \% 2 \mathrm{~F} \% 2 \mathrm{Fwww} . c d c . g o v \% 2 \mathrm{Fsids} \% 2 \mathrm{FAbo}$ utSUIDandSIDS.htm [https://perma.cc/XJE3-9ERK].

189. Sudden Unexpected Infant Death and Sudden Infant Death Syndrome, supra note 155.

190. About SUID and SIDS, supra note 188.

191. Infant Mortality, supra note 31.

192. About SUID and SIDS, supra note 188.

193. Id.

194. Id.

195. Id. 
the risk of Sudden Infant Death Syndrome and Sudden Unexpected Infant Death are related to safe sleep. ${ }^{196}$ These steps include: placing babies on their backs to sleep, avoiding loose bedding and soft surfaces, and only using safe cribs for sleep. ${ }^{197}$ The CDC also recommend regular doctor visits and vaccines for babies as well as use of a pacifier during sleep. ${ }^{198}$

\section{Addressing the risks associated with maternal complications.}

Like other causes of infant mortality, maternal complications highlight the need for early and continuous access to prenatal care. ${ }^{199}$ However, it is also important for some women to have access to care before becoming pregnant. ${ }^{200}$ Maternal complications specifically refer to pregnancy complications. ${ }^{201}$ Maternal complications can occur before and during the actual pregnancy. ${ }^{202}$ Possible maternal complications include: anemia, urinary tract infections, mental health conditions, high blood pressure, diabetes, obesity, infections, and severe nausea and vomiting. ${ }^{203}$ Screening and care prior to becoming pregnant and early in pregnancy can help identify maternal complications for treatment. ${ }^{204}$

Addressing all of the risk factors for infant mortality would be helpful in decreasing the infant mortality rate. According to the CDC, screening, treatment and education are common themes in addressing each of the infant mortality risks. ${ }^{205}$ For example, access to prenatal care can identify nutritional problems in mothers and decrease the risk of low birth weight. ${ }^{206}$

\section{Improve Access to Care}

The common theme in addressing the risk factors of infant mortality is the care, screening, and education associated with prenatal care. ${ }^{207}$ Prenatal care is care received related to a pregnancy. ${ }^{208}$ In 2015 in Indiana, one in eighteen babies

196. Id.

197. Id.

198. Parents and Caregivers, Ctrs. For Disease Control \& Prevention, https://www.cdc. gov/sids/Parents-Caregivers.htm [https://perma.cc/2YMG-SLLM].

199. Pregnancy Complications, Ctrs. For Disease Control \& Prevention, https://www. cdc.gov/reproductivehealth/maternalinfanthealth/pregnancy-complications.html [https://perma.cc/75AQ-5A7J].

200. Id.

201. Infant Mortality, supra note 31.

202. Pregnancy Complications, supra note 199.

203. Id.

204. $I d$.

205. Pregnancy, Ctrs. For Disease Control \& Prevention, https://www.cdc.gov/ pregnancy/during.html [https://perma.cc/6T7W-85KL].

206. Id.

207. See Reproductive and Birth Outcomes, supra note 178.

208. Quick Facts: Prenatal Care, MARCH DiMES Found., https://www.marchofdimes.org/ 
was delivered by a mother who received late or no prenatal care. ${ }^{209}$ Adequate prenatal care includes monthly visits to your healthcare provider until week twenty-eight, bi-weekly visits from week twenty-eight through week thirty-six, and then weekly visits until childbirth. ${ }^{210}$ The frequency of prenatal care visits increases for women with high risk pregnancies. ${ }^{211}$ Prenatal care also includes important screening, testing and education. ${ }^{212}$ Part of the screening and education provided is related to smoking cessation, which is the most preventable cause of illness and death in infants. ${ }^{213}$

There are many resources emphasizing the importance of early prenatal care. ${ }^{214}$ However, it is unclear how Indiana is expanding access to those women who do not seek any prenatal care. For example, what is the state doing to reach the mothers who live in the twenty-five counties in Indiana that are maternity care deserts? $?^{215}$

Another issue related to access to prenatal care is insurance coverage for that care. Maternity care is one of the ten essential health benefits under the Affordable Care Act. ${ }^{216}$ Unfortunately, however, pregnancy is not a life qualifying event that allows enrollment or changes in plans outside of the once per year open enrollment period. ${ }^{217}$ Also, if you have purchased a plan that existed on or before March 23, 2010, it is likely a grandfathered plan and is not required to provide maternity care. ${ }^{218}$ What is the state doing to provide prenatal care for mothers with no insurance coverage or insurance coverage that does not cover maternity care expenses? In 2015, Indiana finally implemented a modified Medicaid expansion, which was extremely important for access to prenatal care for Indiana residents. ${ }^{219}$ However, with eligibility for pregnant women with household incomes up to $208 \%$ of the Federal Poverty Level (FPL), what is

peristats $/$ ViewTopic.aspx?reg=99\&top=5\&lev=0\&slev=1 [https://perma.cc/7BFH-BJ3F]

209. Late/No Prenatal Care: Indiana, 2007-2015, MARch Dimes Found., https://www. marchofdimes.org/Peristats/ViewSubtopic. aspx?reg=18\&top=5\&stop=25\&lev=1\&slev=4\&obj=1. [https://perma.cc/R293-FPT4]

210. Office on Women's Health, supra note 4.

211. Id.

212. Id.

213. During Pregnancy, Ctrs. For Disease Control \& Prevention, https://www.cdc.gov/ pregnancy/during.html [https://perma.cc/D2Y5-DFZS]

214. Office on Women's Health, supra note 4.

215. MARCh OF Dimes Found., supra note 15, at 2.

216. Maternity Insurance Coverage, EHEALTH, https://www.ehealthinsurance.com/maternityinsurance-coverage [https://perma.cc/M6Q5-QN6E]

217. Id.

218. Maternity Insurance for Pregnant Women, Am. PregnanCy Ass'N (Dec. 12, 2017), https://americanpregnancy.org/planning/maternity-insurance-for-pregnant-women/ [https://perma.cc/2A69-SQU3]

219. Indiana and the ACA's Medicaid Expansion, HEALTHINSURANCE.ORG (Mar. 27, 2018), https://www.healthinsurance.org/indiana-medicaid/ [https://perma.cc/3N4D-DKSQ] 
Indiana doing to bridge the gap for women who do not qualify? ${ }^{220}$

Governor Holcomb has stated that Indiana will have the lowest infant mortality rate in the Midwest by $2024 .{ }^{221}$ The Indiana State Health Commission, Dr. Kristina Box, acknowledges that access to prenatal care is important to healthy pregnancies and healthy babies. ${ }^{222}$ Therefore, it is time for more action outside of hospital certifications and safe sleep practices. ${ }^{223}$ The state needs to actually partner with hospitals to provide outreach and access to prenatal care for Indiana residents.

\section{CONCLUSION}

When a woman becomes pregnant, one of the most important steps she will take will be obtaining early and consistent prenatal care. Ideally, a woman will have access to care when she needs it. However, when access to care is limited in Indiana, a hospital certification is unhelpful to expectant mothers who are seeking prenatal care. More important than hospital certifications, is early detection of factors increasing the risk of infant mortality as well as education and interventions to decrease those risks.

Current Indiana legislation requiring certification of birthing centers and hospitals likely will not impact Indiana's infant mortality rate. Indiana legislators need to take an evidence-based and multi-disciplinary approach to determine the best steps for addressing risk factors of infant mortality. Access to care prior to pregnancy, during pregnancy, and after birth will impact infant mortality more than anything else. It is time for Indiana to learn from states with lower infant mortality rates and take steps to provide that care to mothers and babies. Instead of forcing hospitals to pour additional resources into obtaining an unhelpful certification status, we should be supporting healthcare organizations in expanding access to perinatal care.

220. $I d$.

221. Lindsay Moore, State Health Commissioner Talks Infant Mortality, Family Planning and Abortion, J. \& Courier (Apr. 26, 2019), https://www.jconline.com/story/news/2019/04/26/healthcommissioner-infant-mortality-family-planning-abortion/3495764002/ [https://perma.cc/2FMSWAPN].

222. Id.

223. Id. 